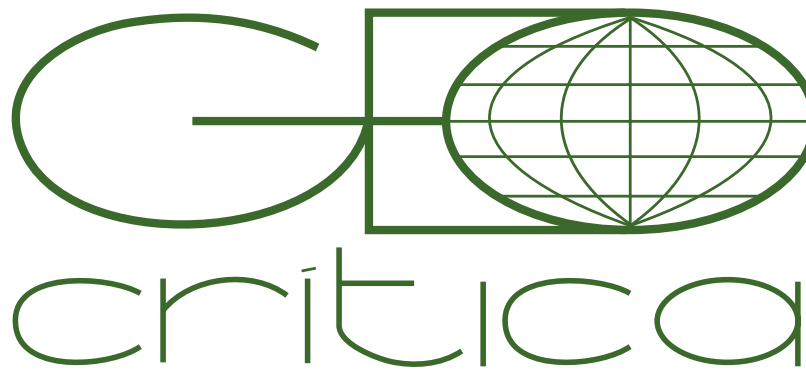

\section{Scripta Nova}

Revista Electrónica de Geografía y Ciencias Sociales Universidad de Barcelona

1 de abril de 2017

\title{
MAPAS PARA EL ESTADO. LA REPRESENTACIÓN DE LA ARAUCANÍA: 1836 -1916
}

Este artículo forma parte de los proyectos Fondecyt № 1130809 "La Araucanía: sujetos y territorio, 1849-1950" y Fondecyt No 1130732 "Relaciones interétnicas y formación del estadonacional en las márgenes: sociedad, frontera y territorio en el espacio transcordillerano Araucanía-Neuquén desde $1883^{\prime \prime}$.
Jaime Flores Chávez

Universidad de La Frontera

jaime.flores@ufrontera.cl

Alonso Azócar Avendaño

Universidad de La Frontera

alonso.azocar@ufrontera.cl

\section{Mapas para el Estado. La representación de la Araucanía: 1836 -1916. (Resumen)}

La construcción y representación del territorio nacional constituyó una de las tareas centrales que abordaron los grupos dirigentes chilenos en el curso del siglo XIX. En este contexto la exploración, ocupación y transformación de la Araucanía pasó a ser uno de los hitos sustantivos, proceso que se reflejó en la dinámica que adquirió la cartográfica del territorio de la Araucanía en el periodo de 1836 a 1916. Si asumimos los mapas como construcciones de la realidad, más que una imagen de la naturaleza, es posible afirmar que el Estado se constituyó en un actor relevante en el proceso de representación cartográfica de la Araucanía a partir de 1836. Con este propósito desplazó agentes "especializados" en representar el territorio, entre otros, naturalistas, militares e ingenieros, que fueron generando una imagen de la Araucanía a partir de sus intereses y discursos específicos. Palabras clave: cartografía, mapas, Araucanía, representación, Estado.

\section{Maps for the State. Representation of the Araucanía: 1836 -1916. (Abstract)}

The construction and representation of national territory constituted one of the central tasks of the Chilean ruling classes during the nineteenth century. In this context, the exploration, occupation and transformation of the Araucanía was one of the key factors, a process reflected in the cartography of the Araucanian territory during the period from 1836 to 1916. Viewing the maps as constructs of reality rather than images of nature allows us to see how the State became a relevant actor in the process of cartographic representation of the Araucanía from 1836 onwards. To this end it sent "specialists" such as naturalists, members of the military and engineers to generate an image of the Araucanía that reflected its specific interests and discourses.

Key words: Cartography, maps, representation, State. 
La construcción y representación del territorio nacional constituyó una de las tareas centrales que abordaron los grupos dirigentes chilenos en el curso del siglo XIX. En este contexto, la exploración, ocupación y transformación de la Araucanía pasó a ser uno de los hitos sustantivos, situación que también se vio reflejada en la representación cartográfica del territorio indígena en el periodo de 1836 a 1916. Con el propósito de analizar esta dinámica, junto a la documentación escrita, hemos utilizado mapas y planos que, a nuestro juicio, constituyen una expresión de los distintos momentos que se pueden observar en el periodo señalado, considerando que, entendemos los "mapas" como dispositivos de poder, intervención, contenedores de proyectos políticos, militares, económicos y menos como artefactos neutros que representan una realidad determinada.

Visto desde este ángulo es posible afirmar que el Estado se constituyó en un actor relevante en el proceso de representación cartográfica de la Araucanía a partir de 1836. Con este propósito desplazó agentes "especializados" en representar el territorio, entre otros, naturalistas, militares e ingenieros. En el periodo que abordamos es posible identificar, al menos, tres momentos: la cartografía efectuada por naturalistas como Claudio Gay e Ignacio Domeyko; aquella que fue producida por los militares como Francisco Vidal Gormaz y Manuel José Olascoaga; finalmente, la que construyeron los "ingenieros" representados en la figura de Nicanor Bolonia.

Esta cartografía es la expresión del contexto por el que transitó la historia de la Araucanía, una primera etapa marcada por la exploración, a la que sigue una en que lo determinante fue la acción militar que concluyó con la derrota mapuche y, finalmente, la llegada masiva de nuevos habitantes y los diversos dispositivos y agentes estatales al territorio, intensificando el proceso de ocupación y transformación del mismo. En este sentido los planteamientos J. B. Harley, respecto del análisis de la cartografía, han orientado nuestro trabajo, en orden a contemplar tres aspectos, a saber: el primero, el contexto del cartógrafo; segundo, los contextos de los otros mapas y tercero, el contexto de la sociedad.

Para este trabajo hemos efectuado una revisión de diversos archivos como el Archivo Nacional Histórico, el Archivo Nacional de la Administración, Archivo Regional de la Araucanía, Archivo Histórico de Angol, el Archivo de Bienes Nacionales, Archivo del Ministerio de Obras Públicas, Archivo de la Nación Argentina, la Biblioteca Nacional y Biblioteca de la Universidad de Concepción. Esta amplia y diversa compilación de fuentes nos permitió reunir un número significativo de planos y cartas referidas a la Araucanía, las que fueron digitalizadas, ordenadas y clasificadas conformando un corpus inicial, del que hemos seleccionado algunos mapas para la materialización de este artículo. 


\section{Territorio, mapas y representación}

Ante la pregunta de ¿qué es un mapa? J. B. Harley señala que son "textos mas que una imagen de la naturaleza" agregando que "Los mapas son textos en el mismo sentido en que los son otros sistemas de signos no verbales como los cuadros, las impresiones, el teatro, el cine, la televisión y la música... los mapas son un lenguaje gráfico que se debe decodificar. Son una construcción de la realidad, imágenes cargadas de intenciones y consecuencias que se pueden estudiar en las sociedades de su tiempo. Al igual que los libros, son también producto tanto de las mentes individuales como de los valores culturales más amplios en sociedades específicas." ${ }^{1}$

En esta misma línea, Norman Thrower observa que la historia de la cartografía "refleja bastante bien el estado de la actividad cultural, así como la percepción del mundo en diferentes periodos." ${ }^{2}$ Distante de pensar el mapa como un producto meramente técnico, neutro ya histórico sostiene que éste "refleja el pensamiento cambiante de la especie humana, y pocas de sus obras constituyen un indicador tan excelente de la cultura y civilización." 3 Adhiriendo a los planteamientos de McLuhan argumenta que el mapa es uno de los elementos que forman parte de un selecto grupo de medios de comunicación sin los cuales "el mundo de la ciencia y las tecnologías modernas difícilmente podría existir"4. De tal forma que los mapas, "son los objetos que comunican visualmente un sentido real o imaginario del entorno geográfico, por lo que son, en efecto, una expresión representacional de dicha comprensión o percepción espacial" como lo plantea José García Redondo 5 .

Más aún, al contrario de lo que pensamos "El mapa precede al territorio", sostiene Franco Farinelli, "En la escuela, agrega, nos han enseñado algo que es profundamente incorrecto, que un mapa geográfico es una copia de la realidad. En cambio es exactamente lo contrario." ${ }^{6}$ Es posible pensar que ¿el mapa de Chile, precede al territorio nacional?, ¿que el mapa de la Araucanía es anterior a su territorio? o ¿que el plano es anterior al pueblo?

Pero el mapa es algo más, sostiene Harley, éste puede ser visto como poder-conocimiento, pasando a ocupar un lugar fundamental en los discursos coloniales. Al respecto apunta que el poder del mapa estriba en su capacidad de constituir "un acto de control de la imagen del mundo... Desde la época de Colón, los mapas han contribuido a crear alguno de los estereotipos más dominantes de nuestro mundo" afirma este autor. ${ }^{7}$ Misma línea seguida por el arquitecto catalán, Manuel de Solà-Morales,

1 Harley 2005, p. 62.

2 Thrower 2002, p. 11.

3 Idem.

4 Idem.

5 García 2014, p. 17.

6 Farinelli, (En línea): <https://www.youtube.com/watch?v=3xY6zwc RlU\&list=PLxxdHWzDFi9WPnL7 EHMbjfcrtOmPA1D8\&index=4 $>$ (22 de octubre 2015) Ver también Lladó, Bernat. Franco Farinelli. Del mapa al laberinto. Barcelona: Icaria, 2013.Analiza el pensamiento de Farinelli e incorpora algunos artículos de este autor.

7 Harley 2005, p. 62. 
al sostener que en el pasado, así como en el presente, los mapas son una "auténtica creación ideológica", los cuales más que describir la realidad la definen, siendo capaces de inventar y proponer "el universo en el acto mismo de reproducirlo... esta es la gran fuerza política y teórica de la imagen cartográfica".

Son la materialización de estas características las que observa Harley en el caso norteamericano, para 1677 "la tendencia a erradicar la geografía india había dado otro paso" al nombrar de manera occidental los lugares y sancionarlos en los mapas. Los indígenas "usaban etiquetas ecológicas para describir posibles usos de la tierra" en tanto los nuevos nombres eran arbitrarios y asociados a personas. Esto nos lleva a que la toponimia también constituye una vía para el análisis de los mapas. ${ }^{9}$ Pero además, el estudio cartográfico sobre México de Raymond Craib, avanza en la idea que los mapas estatales constituyeron una forma de "fijar los espacios fugitivos" propios del mundo indígena. ${ }^{10}$ Un fenómeno observable en procesos similares en otras latitudes.

Esta capacidad del Estado para ir conformando una imagen del territorio nacional constituye una de las preocupaciones de Verónica Hollman y Carla Lois, señalan que "El cuerpo de la nación y su silueta territorial se transformaron en lo que Benedict Anderson denominó el "mapa-logotipo""11, por la infinita capacidad de ser reproducido en carteles, sellos oficiales, revistas, libros, "Así el mapa anticipó la concretización de la nación en tanto comunidad imaginada." ${ }^{12}$ En Argentina esto ocurrió a partir de la segunda mitad del siglo XIX y su preocupación por mantener el control de su circulación se mantiene hasta el presente. Esta importancia queda expresada en los libros escolares y la enseñanza de la geografía argentina en el sistema escolar que se despliega en un "esquema cartográfico". ${ }^{13}$

En Chile diversos autores han abordado el estudio de la cartografía entre otros resultan provocadores el notable trabajo sobre la cartografía de Chiloé de Gabriel Guarda y Rodrigo Moreno ${ }^{14}$; José Ignacio González y su estudio sobre los primeros levantamientos cartográficos generales de Chile, ${ }^{15}$ y en asociación a Patricio Bernedo la importancia de la cartografía en la representación de procesos históricos. ${ }^{16}$ Los estudios de Rafael Sagredo sobre Claudio Gay y la representación de Chile ${ }^{17}$ y, junto a Rodrigo Moreno como coordinadores del libro El Mar del Sur en la historia, un conjunto de trabajos cuyo eje es la geografía y la representación del territorio en torno

8 De Solà-Morales [En línea] <http://lub.upc.edu/web/Arxiu/Recerques/comarques/articles_castella/identidad_territorio_cast.pdf $>$ (25 de enero 2016)

9 Un aspecto que también es posible observar en la cartografía de la Araucanía.

10 Craib 2004.

11 Hollman y Lois 2015, p. 68.

12 Idem.

13 Idem.

14 Guarda y Moreno 2010.

15 González 2007, pp. 21-44.

16 González y Bernedo 2013, pp. 179-198.

17 Sagredo 2008. Del mismo autor “El Atlas de Gay. La representación de una nación", en Gay 2010, Tomos I y II. 
al Océano Pacífico. ${ }^{18}$ La obra de Rolf Foerster, Cristian Moreno y Jimena Ramírez que aborda el tema del conflicto sobre las tierras en que la documentación cartográfica juega un rol central. ${ }^{19}$

El estudio sobre la Cartografía Histórica de ChileEelaborado por Jaime Rosenblitt y María Sanhueza ${ }^{20}$, establecen dos momentos en los estudios geográficos y cartográficos, la primera mitad del siglo XIX marcados por la necesidad de reconocer y cartografiar las divisiones político administrativas internas del territorio y la segunda mitad de este siglo marcada por la definición de las fronteras nacionales. ${ }^{21}$

\section{Exploraciones y construcción cartográfica}

Luego de la independencia de Chile, una de las tareas que debió enfrentar el grupo gobernante fue el reconocimiento de su territorio y la construcción de mapas que lo representaran adecuadamente. La construcción de una nación demandaba una imagen de éste ya que, como sostiene Manuel de Solà-Morales "todo proyecto político necesita de esta conciencia territorial" ${ }^{22}$, además una buena administración de la república hacia imprescindible tener información más acabada de sus población y su territorio, ¿cuántos somos?, ¿dónde se localizan?, ¿cómo es el relieve?, ¿cuáles son los ríos y montañas?, ¿dónde se ubican? Constituyeron algunas de las preguntas a las que era necesario dar respuesta. La materialización de los censos de la nación significó una respuesta para avanzar sobre las interrogantes referidas a la población y el levantamiento cartográfico, avanzar sobre la espacialidad del país, tarea que se proyecta hasta el presente. Dar cuerpo a la nación se constituyó en un desafío y una necesidad apremiante, la cartografía existente era inexacta, poco conocida y estructurada al amparo de propósitos propios del mundo colonial ${ }^{23}$.

La necesidad de suplir esta carencia llevó al Director Supremo Ramón Freire encomendar un viaje científico a Juan José Dauxion Lavaysse. En 1823 se desplazó por toda la república con el objeto de recabar diversa información que permitiera contribuir a formar una "exacta estadística de Chile". Ese mismo año el gobierno mandó a levantar una carta geográfica de Chile al Coronel de ingenieros Alberto D’Albe y al ingeniero geógrafo Carlos Ambrosio Lozier. Por diversos motivos los resultados no fueron los esperados y la información, así como la cartografía, continuó siendo una tarea pendiente. ${ }^{24}$

En este contexto es contratado Claudio Gay por el gobierno de Chile. Entre las tareas asignadas estaba la de confeccionar un mapa de la naciente república ${ }^{25}$. Como resultado de sus recorridos científicos por Chile y la Araucanía, publicó una serie 18 Sagredo y Moreno 2014.

19 Foerster et al. 2014.

20 Rosenblitt y Sanhueza 2010, tomo 41.

21 Rosenblitt y Sanhueza 2010, p. 24.

22 De Solà-Morales La identidad del territorio, (en línea) <http://lub.upc.edu/web/Arxiu/Recerques/comarques/articles_castella/identidad_territorio_cast.pdf $>$ (26 de octubre de 2015) 23 Sobre la representación del territorio chileno ver Núñez 2009. Sagredo 2008 y 2010.

24 Barros Arana 1909-1911, v. 5, pp. 239-457. Para mayores detalles respecto de los personajes al que hemos hecho referencia, ver páginas 245 a 269.

25Sobre el aporte cartográfico de Claudio Gay ver González 2007, pp. 21-44. 
de artículos en periódicos y revistas científicas, sin embargo su obra máxima fue la Historia física y política de Chile. Según documentos adquiridos en esta república durante doce años de residencia en ella y publicada bajo los auspicios del supremo gobierno. ${ }^{26}$

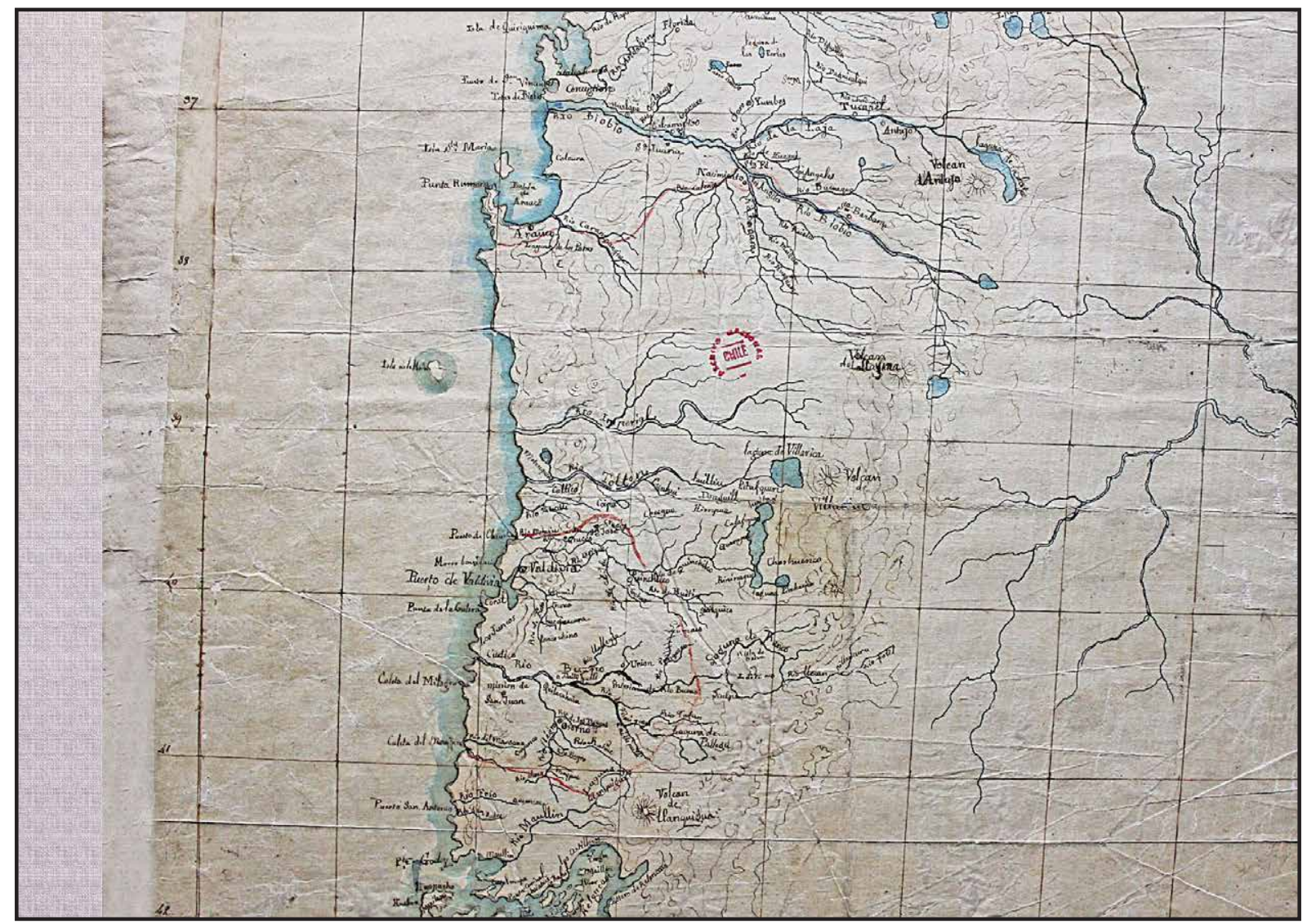

Figura 1.Claudio Gay, detalle del mapa "Borrador de un mapa de Chile" 1836.

En el caso de la Araucanía, tres fueron los viajes que realizó a dicho territorio. El primero entre 1834-1835, el segundo entre $1838-1839$ y el tercero en $1863^{27}$. Pero ya en 1836 entrega un "Borrador de un mapa de Chile"28 (figura 1, detalle), a su juicio, bastante exacto respecto de los existentes. Este será la base del que, en 1854, fue publicado en su Atlas de la Historia Física y Política de Chile y que denominó "Mapa para la inteligencia de la Historia física y política de Chile". En el Borrador resulta relevante que el territorio mapuche se integra en el continuo del territorio nacional, aun cuando en los hechos esto no acontecía. Situación que quedó impresa en

26 La extensa obra fue publicada en París-Chile entre 1844 a 1871, está compuesta por treinta volúmenes a saber: ocho tomos de Historia y dos de documentos; ocho de Botánica; ocho de Zoología; dos de Agricultura; y un Atlas con cartas generales y provinciales, alo que sumaba gravados y láminas en dos tomos. Sin duda, esta voluminosa obra se constituyó en uno de los pilares fundamentales de la visibilización de Chile en General y la Araucanía en particular.

27 Flores 2015, pp.189-209.

28 Sobre este "Borrador del mapa de Chile" y la obra cartográfica de Gay véase Sagredo 2010, Tomos I y II. En las páginas Lxii y Lxiii se reproduce este "Borrador", además hemos consultado el original ubicado en el Archivo Nacional Histórico, Mapoteca, No 7, Mapa de Chile por Gay, Archivo Gay, vol 79, fojas 7. (Nueva clasificación MI-B6-D1.1.) 
el mapa de 1854. Cabe señalar que el Borrador destaca la hidrografía del territorio como un rasgo central, los ríos "Biobio" y sus afluentes como el "río de la Laja" y el "Río Bergara"; el "río Imperial" al que fluyen otros tributarios pero que no son identificado; el río Tolten con alguno de sus afluentes y que nace de la "laguna de Villarrica"; el río Cruces. De los lagos cordilleranos son identificado la "laguna de La Laja", "laguna de Villarrica", "laguna de Pirehaeico", los lagos Calafquén y Panguipulli se dibujan unidos y sin identificarlos, sí algunos lugares en su entorno como "huitag", "Calafquen", "Choshuenco", "Rininague". Al norte dos lagunas, sin denominación, son dibujadas como el lugar de donde nace el río BíoBío. De los volcanes son identificados el Antuco, "Llayma”, Villarrica. Se dibujan unos cursos de agua que desde la cordillera van en dirección Este sin identificarlos.

El Borrador está cuadriculado con paralelos y meridianos y al costado derecho, al margen del territorio representado, se va identificando las provincias correspondientes desde Copiapó hasta Chiloé. Entre la Provincia de Concepción y la Provincia de Valdivia se escribe "Araucania", coincidentemente es el espacio que contiene menos referencias topográficas e hídricas, y salvo Arauco, Cruces y San José, no se observa alusión a su población, es el "espacio en blanco" del mapa, el que entrega menos información.

En el caso del "Mapa para la inteligencia de la Historia física y política de Chile" publicado en 1854, a juicio de Rafael Sagredo "se convirtió en verdadero logotipo del Estado-nación", al ser reconocido y transformarse en distintivo propio de Chile, penetró profundamente en la mentalidad colectiva, y no sólo a nivel nacional" ${ }^{29}$. En lo que toca a la Araucanía es necesario destacar que incorpora un texto que señala "Indios Independientes" sobre un territorio que va desde la "Laguna de Ranco" por el sur hasta el río BíoBío por el norte, en clara alusión al pueblo mapuche que habitaba dicha zona.

En este sentido es posible pensar que, si bien el trabajo cartográfico de Claudio Gay se sustentó en la recopilación de información que efectuó a partir de sus exploraciones, así como de otros documentos, informes y mapas producidos por otros, en definitiva, basado en una "realidad concreta" de la geografía física. En tanto, el producto final, asociado al "Borrador de Chile" y al "Mapa para la inteligencia de la Historia física y política de Chile" se constituyeron en un discurso sobre Chile, un proyecto que como tal conformaba una imagen de lo que debería ser, más que la concreción de lo que era. En este sentido, pensamos que la Araucanía, al ser incorporada en la representación general de Chile, era dibujada como un "espacio en blanco" en el mapa el que debía ser completado, o un territorio de los "Indios Independientes" que debían ser sometidos para lograr hacer consistente el cuerpo (completo) de la nación. Asumiendo el planteamiento de Franco Farinelli, de alguna forma el mapa precedía al territorio de Chile, a lo menos en lo que a la Araucanía se refiere.

29 Sagredo 2010, p. Lxxii. 


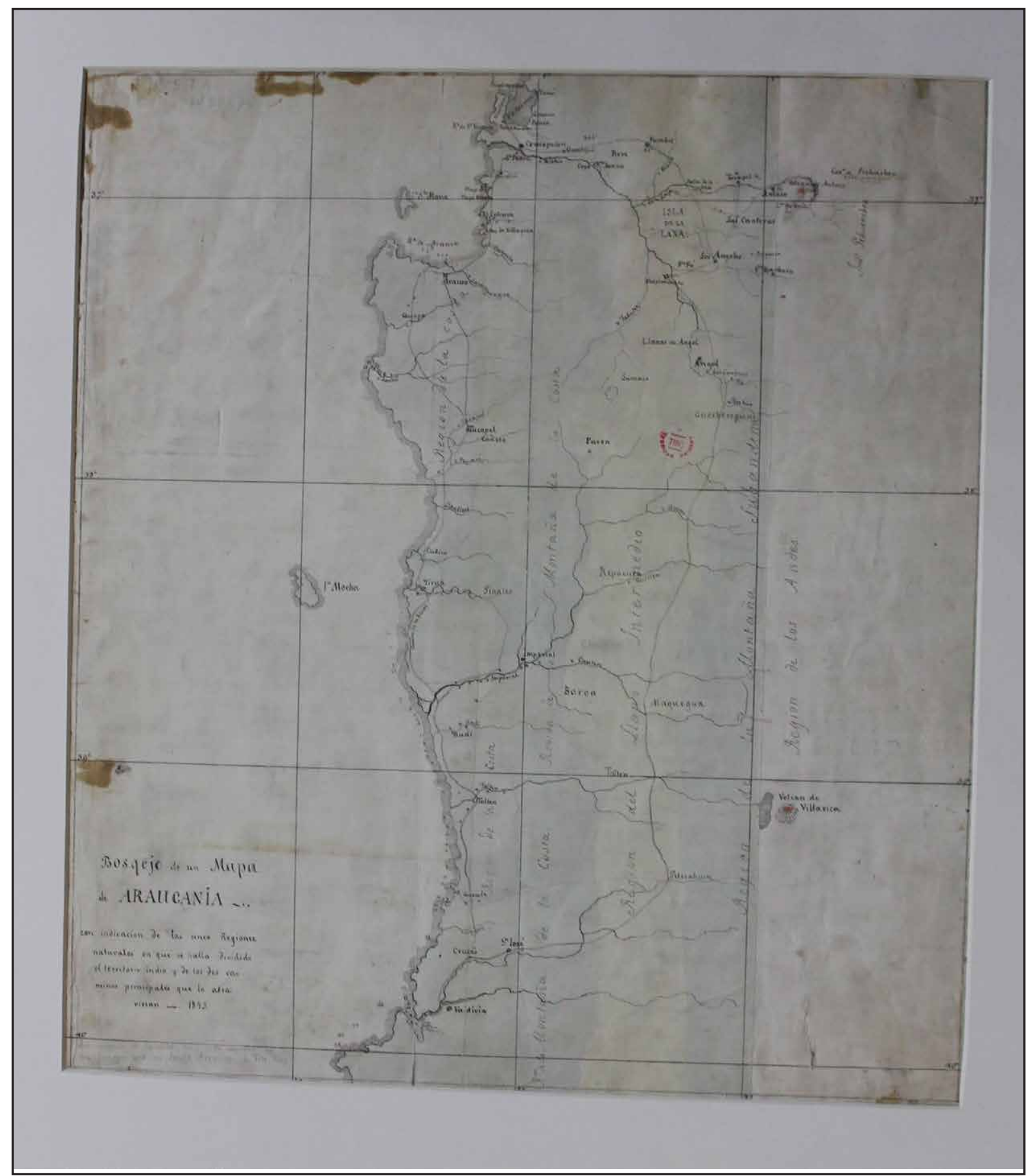

Figura 2. Ignacio Domeyko, mapa "Bosquejo de un mapa de Araucanía", 1845.

Luego de recorrer el territorio mapuche, en 1845 el naturalista polaco Ignacio Domeyko confeccionaba un mapa de la Araucanía que denominó "Bosquejo de un mapa de Araucanía". Con indicaciones de las cinco regiones naturales en que se halla dividido el territorio indio y de los dos caminos principales que lo atraviesan. 1845." ${ }^{\prime 30}$ (figura 2) Es un mapa que abarca el territorio comprendido entre la ciudad

30 Archivo Nacional Histórico. Fondo Mapoteca, No 11, Mapa Araucanía. FA (Fondo Antiguo), vol. 
de Concepción y el río BíoBío por el Norte y, la ciudad de Valdivia y río San Pedro por el Sur. Hacia el Este está limitado a la "Región de los Andes". Como señala su título, bosqueja en la Araucanía cinco regiones naturales que estarían orientadas en un sentido norte-sur, desde el Oeste hacia el Este serían: "Región de la Costa", "Región de la Montaña de la Costa", "Región del Llano Intermedio", "Región de la Montaña Subandina" y "Región de Los Andes".

Entre los aspectos naturales Domeyko da cuenta de la hidrografía destacando los ríos BíoBío, el Imperial-Cauten, y consignando algunos de sus afluentes. De los volcanes, deja estampado la presencia del Antuco y Villarrica a los que les pinta su cráter de color rojo aludiendo, seguramente, a la lava que emanaba de ellos durante las erupciones. De los lagos y lagunas existentes en este espacio sólo consigna el lago Villarrica.

Entre los aspectos culturales el naturalista identifica los dos principales caminos que cruzaban la Araucanía de norte a sur, el de la costa y el que se dibujaba por el "Llano Intermedio", los que destaca en el título de su mapa. También identifica sectores, el mayor tamaño de la letra hace destacar a unos por sobre otros (alusión, seguramente, a su importancia), así es posible identificar Boroa, Maquegua y los Llanos de Angol, con una jerarquía mayor que Lumaco o Pelecahuin. Con un punto busca dar mayor precisión a otros lugares como es el caso de antiguas ciudades de la conquista como Angol, Puren, Tucapel, Imperial, otros como Tirua, Budi, Tolten, Queule, Cruces y San José tiene una jerarquía menor. Sin duda que este resulta un aspecto significativo en tanto estos lugares localizados en el mapa aluden a asentamientos poblacionales de mayor o menor relevancia que existieron o constituían incipientes agrupaciones de población. Una suerte de anticipación a la fundación de misiones, fuertes y pueblos de una futura conquista, algo de lo que los mapuche eran tenaces opositores como lo pudo comprobar Domeyko en su viaje por la Araucanía. La precisión no era su objetivo, sino la representación del territorio indígena, su reducción en un "papel".

En 1846 toma forma un nuevo mapa el "Mapa de la Provincia de Valdivia según los datos de la estadística qe se han podido recoger hasta ahora, construida por Bernardo E. Philippi"31 (figura 3). Esta carta es el resultado de exploraciones de Philippi, así como de otras informaciones de segunda mano recopiladas por él de la provincia de Valdivia. Esta abarca desde el río Toltén por el Norte hasta parte de la Isla de Chiloé por el Sur. Hacia el Este se señala el límite con la República de Argentina, un aspecto no menor habida cuenta que las demarcación definitiva constituirá un aspecto gravitante de la política binacional a partir de fines del siglo XIX hasta el presente. Es una carta que busca dar claridad respecto de los límites administrativos de las provincias de Valdivia y Chiloé con sus subdivisiones de Departamentos y Subdelegaciones.

En lo que toca a la Araucanía, si observamos la sección que va de la ciudad de

33, p.7, fecha $1845,43,5 \times 51 \mathrm{~cm}$.

31 Archivo Histórico Nacional, Mapoteca, № 294, Mapa de la provincia de Valdivia, Ministerio del Interior vol. 262 fs.l fecha octubre de 1846, mide 44 x 59,3 cm. 
Valdivia al norte, lo que se identifica como el Departamento de Valdivia, un aspecto que resulta relevante es la leyenda que señala "De aquí para el norte principian los Araucanos independientes" texto ubicado a la altura del río Leufucague (tributario del Cruces) a la altura de la Punta Chanchán. Lo relevante es el intento de definir una frontera sur, aunque poco precisa, de carácter más político que natural en la medida que este límite no es asociado a ningún hito geográfico destacado en el mapa. Una intento por ir fijando estos "espacios fugitivos" en un mapa por parte de los agentes del Estado chileno.

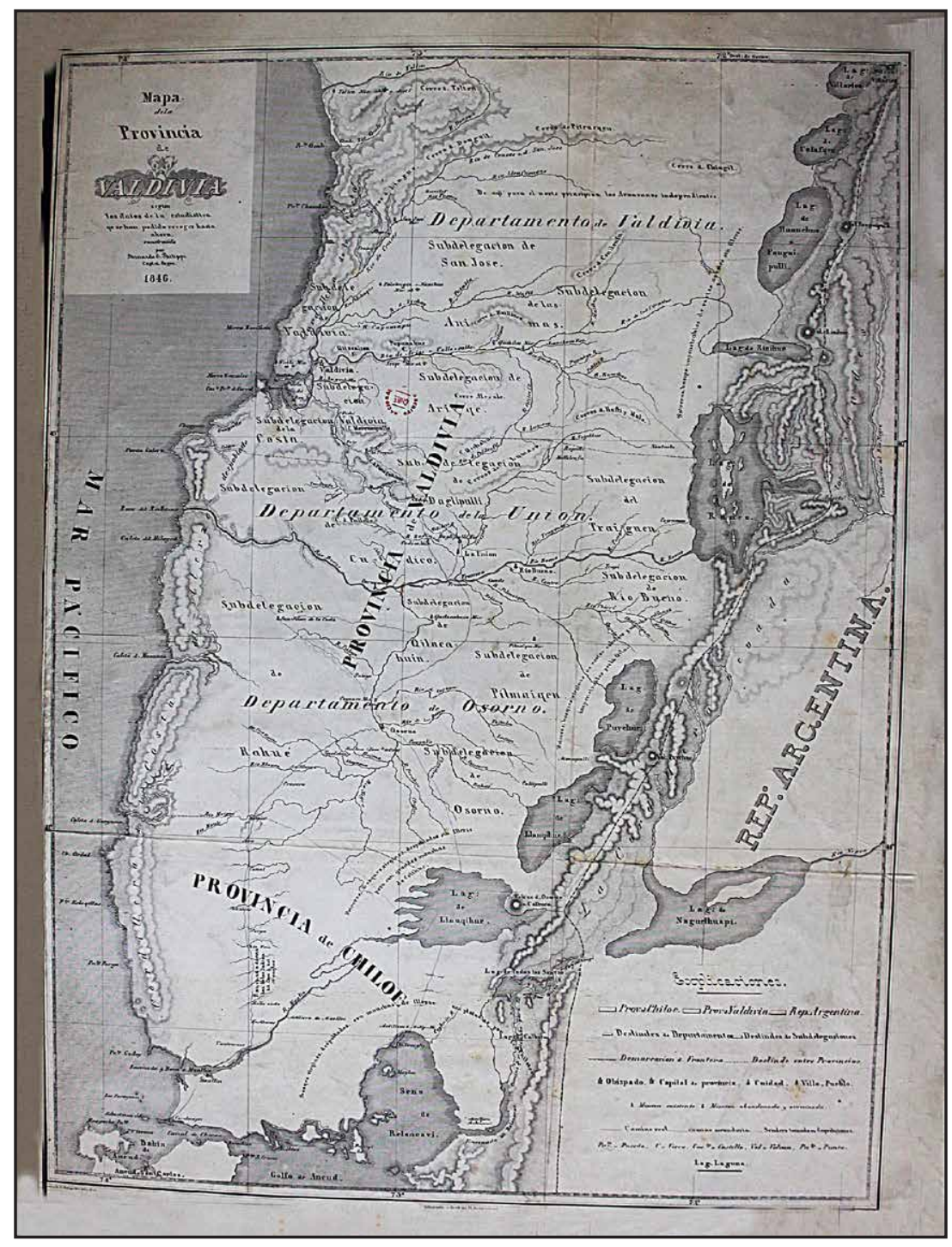

Figura 3. Bernardo E. Philippi, "Mapa de la Provincia de Valdivia”, 1846.

Al Norte de este "límite" se identifican y localizan lagunas como las de Calafquen y Villarrica, el volcán homónimo, los Cerros de "Chingil", "Pitrusquen", "Donguil", Tolten, y los ríos Toltén, Queule, Donguil "Cruces o de San José" y “Lleufucague". El único hito asociado a un aspecto cultural es la referencia a la misión de Toltén "misión abandonada y arruinada" como destaca su simbología y refrendado con el texto 
en dicho lugar.

\section{Mapa, territorio y control militar o ¿la derrota indígena?}

Generalmente se asocia la ocupación militar de la Araucanía a las acciones bélicas desarrolladas por el ejército en el periodo comprendido entre los años 1862 y 1883 cuyos hitos son las refundaciones de las ciudades de Angol y Villarrica, respectivamente. Ambas ciudades habían sido fundadas durante la Conquista y deshabitadas luego del levantamiento general indígena de fines del siglo XVI. No obstante, estas acciones militares estuvieron precedidas y acompañadas por otras de un carácter distinto, pero fundamentales para lograr el objetivo de derrotar a los mapuche. La exploración y representación del territorio fueron gravitantes en la organización y planificación de las campañas militares, tarea en que participaron hombres de la Marina y el Ejército.

Para mediados del siglo XIX la economía era más dinámica y ello se traducía en un mayor tráfico marítimo que conectaba los diversos puertos nacionales e internacionales. Una navegación segura demandaba un mejor conocimiento del litoral y el levantamiento de una cartografía acorde con los nuevos tiempos. Por ende, la exploración de la costa y el curso de ríos y lagos, constituyó una tarea de gran envergadura en el proceso de ir configurando un territorio nacional. Este aspecto se acentuaba en la Araucanía, era un territorio dominado por indígenas del cual se tenía menos referencias que el resto del país. Además, aumentaban las voces que señalaban que había llegado la hora de integrarlo al resto de la nación. ${ }^{32}$

Por ello las exploraciones a la costa de la Araucanía comenzaron a ser más frecuentes a partir de mediados del siglo XIX. Para efectos de nuestro trabajo nos interesa destacar los productos cartográficos que generaron algunas de ellas, entendidas como parte un proceso que iba en la dirección de configurar con mayor precisión el territorio nacional, a la vez que constituían materiales sustantivos en el proceso militar de derrota mapuche.

Por su importancia y el sentido de este trabajo nos detendremos entre de ellas. La primera, la "Expedición a los ríos del Sud", que zarpó desde Valparaíso el 20 de diciembre de 1854 en los vapores "Cazador" y "Maule", era comandada por el Capitán de Fragata L. Señoret, su objetivo central era el reconocimiento de la boca del río Imperial y la exploración del mismo "a fin de obtener datos fijos i seguros sobre las dificultades de su entrada i la capacidad que presenta en sus aguas a la navegación, i sus orillas, i el pais que atraviesa al establecimiento de puestos militares fortificados, establecimientos industriales o una población." ${ }^{33}$

En el punto octavo de sus instrucciones se hacía ver que, dicho reconocimiento, debía efectuarse con toda la "prolijidad posible en la parte hidrográfica, con levan-

32Al respecto ver Leiva 1984; Pinto 2003.

33Archivo Regional de la Araucanía (A.R.A.), Memoria del Ministro de Marina (M.M.M.) 1855, Imprenta de la Sociedad, Santiago, 1855. Instrucciones dadas al Jefe de la Expedición a los rios del Sud Capitán de Fragata don Leoncio Señoret por parte de Pedro Nolasco Vidal. Santiago, diciembre 16 de 1854.p. 31. 
tamiento de planos, indicaciones de sondas etc. etc.; pero en la parte topográfica, a la simple vista i sin dar lugar a sospechas o desconfianza de los Indios". ${ }^{34}$ Reiterando que la comisión expedicionaria debía tener cuidado de no causar "alarma o inquietud" entre los mapuche.

A esta expedición siguió otra a finales de febrero cuyo el objeto era efectuar, nuevamente, un "prolijo reconocimiento de los rios, Imperial, Budi i Tolten, explorándolos hasta donde sea posible a fin de obtener datos fijos i seguros sobre las dificultades de su entrada i la capacidad que presenten sus aguas a la navegación i sus orillas i el pais que atraviesen, al establecimiento de puestos militares fortificados, misiones evangélicas, establecimientos industriales i poblaciones"35

Junto al Estado, se hacía parte en la expedición la Iglesia Católica en la persona del Prefecto Apostólico Capuchino Padre Anjelo ${ }^{36}$ de quien, se señalaba, sería de mucha utilidad a la empresa dado "El carácter que inviste i el conocimiento que el Padre Superior tiene de aquellos lugares." Además se instruía que, si del reconocimiento practicado los mapuche actuaban amistosamente, se debería desembarcar a los religiosos esperando ver si los misioneros optaban por quedarse o embarcarse, en el primero de los casos los auxiliarían para construir sus habitaciones. Durante la espera, se les instruyó para que examinasen un lugar más conveniente al establecimiento de un puerto, barra adentro y de alguna rada abrigada, barra afuera. ${ }^{37}$ Nuevamente los vapores de guerra "Cazador" y "Maule" emprendían proa al sur a cargo del Capitán Cabieses y el Guardia Marina Olavarría. El día 28 de febrero zarpaban desde Valparaíso rumbo a la costa mapuche.

Uno de los productos de estas exploraciones fue el "Plano de la Costa de Chile i de los Ríos Reconocidos en la Campaña de Exploración Hecha de Orden del Supremo Gobierno en Marzo 1855 con los Vapores de Guerra Cazador i Maule. Levantado por el Capitán de Ing. ${ }^{\text {s }}$ Donoso, los Tenientes de Marina Rodgers, Hurtado i Costa, i anotado por el Jefe de la Expedición", (figura 4). Las "Explicaciones" o simbología advierten que "los números de las sondas expresan brazas en el mar i en los puertos, pero pies en las barras i en los rios", un ancla da cuenta de los lugares donde fondearon los vapores y otra más pequeña donde lo hizo sólo el "Maule". Una línea punteada referencia el "Camino que han andado los Exploradores, a pie, a caballo, en bote i en los Vapores". Un icono rectangular fijaba la ubicación "sitios a propósitos para ciudades i fortalezas"; el de una casa "Lugar para colocar el practico del Tolten"; Una letra A señalaba el "Fondo de Arena" y una G el "Fondo de Guijos"; un circulo con una cruz encima daba cuenta de las "Casas habitadas por Misioneros"; una especie de asterisco el "Punto de la costa cerca del Imperial en que se ha varado el Maule"; una P "Laguna propia para un puerto al abrigo de avenidas". "Establecimiento de puerto $10 .{ }^{\mathrm{h} 1 / 2}$ de la mañana. Elevación de la marea $41 / 2$ pies".

34 Ibíd. p.32.

35 A.R.A., M.M.M. 1855, Instrucciones dadas al Jefe de la Expedición a los rios del Sud en el segundo viaje emprendido. Santiago, febrero 26 de 1855. p. 44.

36 En otros documentos se castellaniza su nombre llamándolo Padre Angel.

37 A.R.A., M.M.M. 1855, Instrucciones dadas al Jefe de la Expedición a los rios del Sud en el segundo viaje emprendido. Ministerio de Marina Pedro Nolasco Vidal. Santiago, febrero 26 de 1855. p. 45. 
El mapa comprende el espacio litoral entre la Boca del Río Imperial, por el Norte y el Cabo Bonifacio, por el Sur. Para 1855, constituye una representación actualizada que busca proporcionar, por una parte, información detallada y precisa para una navegación segura y por otra, identificar puntos específicos para la ocupación militar del territorio. Ello explica la localización de las misiones capuchinas de Queule e Imperial, esta última había sido fundada cinco años antes y constituía un punto clave para el proceso de reconocimiento del territorio, al mismo tiempo que los religiosos proporcionaban información relevante y una cuartada para la presencia de militares que inquietaba a los mapuche, como queda expresado en los informes de los exploradores.

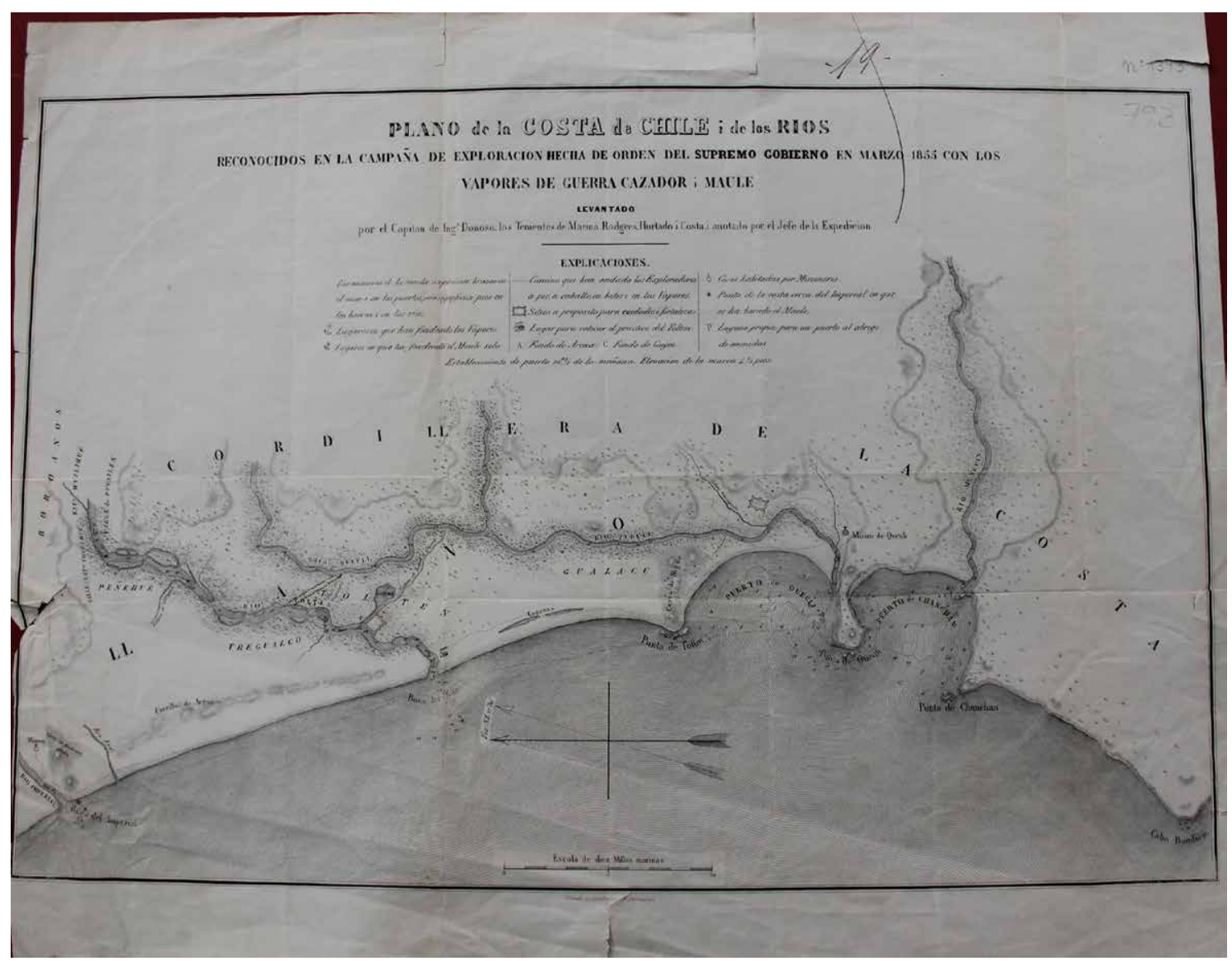

Figura 4. Donoso, Rodgers, Hurtado i Costa, "Plano de la Costa de Chile", 1855.

Como la navegación comercial y militar se había intensificado, la búsqueda de lugares seguros para fondear pasaba a ser gravitante, al igual que el reconocimiento del curso de los ríos que penetraban en tierras indígenas. Pero el mapa también proyectaba la ocupación que se venía, al identificar la profundidad de la costa y de los ríos, y establecer con precisión los lugares donde se deberían instalar los futuros fuertes militares, lo que se concretó algunos años más tarde. El mapa contenía y era la expresión de la ciencia y la técnica traídas a la Araucanía por los conquistadores del siglo XIX y utilizada con el propósito de derrotar a los mapuche. Las exploraciones a la costa de la Araucanía continuaron, entre ellas destacó la "Exploración 
hidrográfica de la costa de Arauco" desarrollada a fines de 1866 y principios de 1867, su materialización estuvo marcada por factores externos e internos que habían llevado a las autoridades chilenas a desarrollar una fuerte ofensiva conquistadora. La Guerra del año 1866 con España, habían develado la vulnerabilidad de Chile al tener un territorio, como la Araucanía, sin un dominio efectivo, situación que había generado dificultades de desplazamiento de soldados, desde el norte del río Bío-Bío a las plazas de Valdivia y Chiloé. De igual forma, la existencia de una franja costera sin presencia militar chilena, mostraba un flanco de penetración para los potenciales enemigos externos. Se fortaleció la voz de quienes propiciaban una ocupación rápida y definitiva de la Araucanía, para lo cual era necesario aumentar los esfuerzos y recursos.

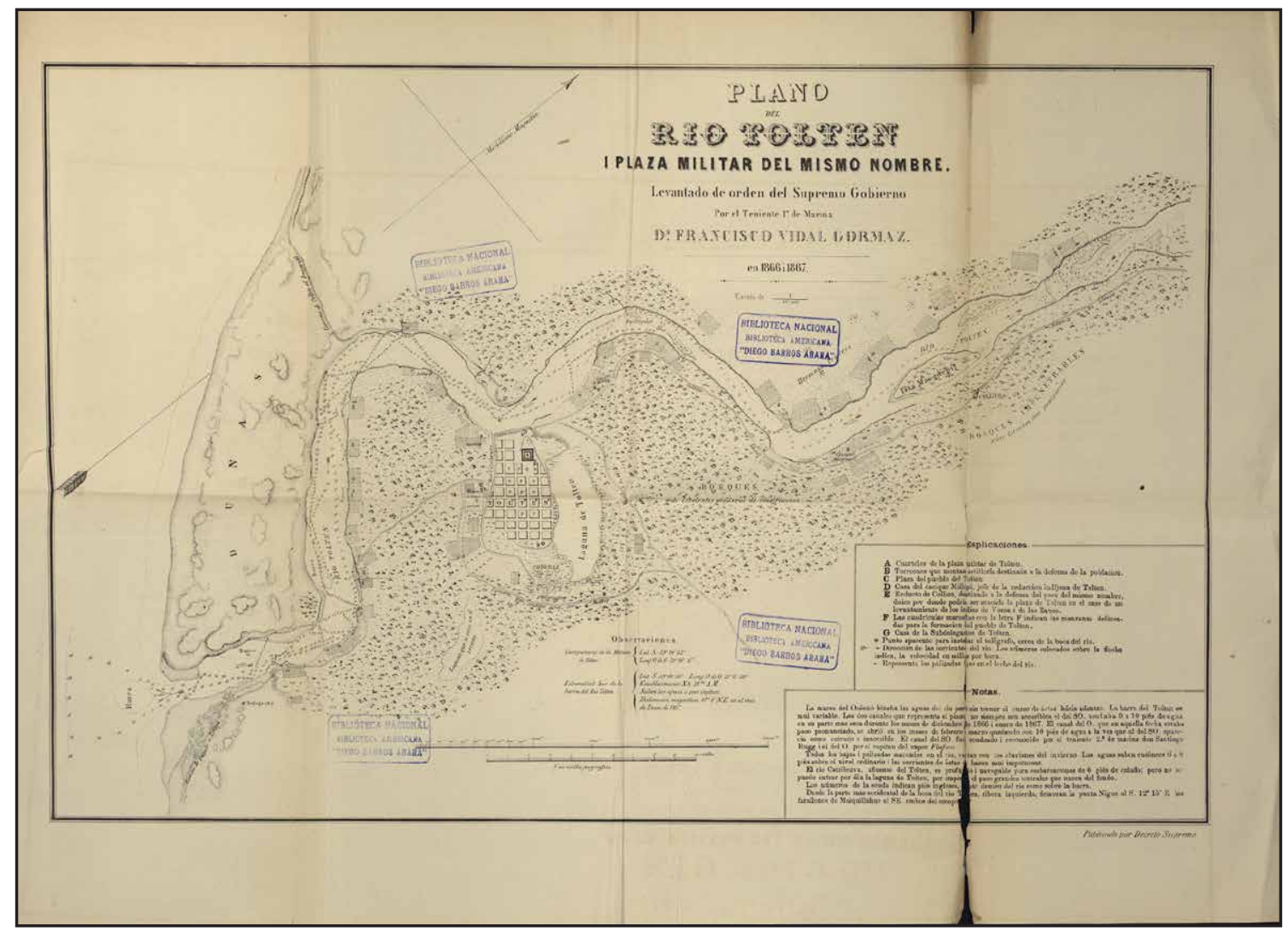

Figura 5. Francisco Vidal G., "Plano del Rio Tolten i plaza militar del mismo nombre”, 1867.

Con este fin, se buscó consolidar la línea del río Malleco establecida hacia 1862 y constituir al río Toltén como frontera sur, acción que buscaba evitar incursiones indígenas hacia la ciudad de Valdivia. Para ello era necesario, consolidar el fuerte de Toltén y siguiendo el río homónimo, llegar hasta las míticas ruinas de la ciudad de Villarrica, estableciendo, entre ambos puntos, una serie de emplazamientos militares. Además era el año en que se proponía ocupar todos los puertos y caletas de la costa de la Araucanía, para evitar cualquier amago de un "enemigo exterior" sobre aquel litoral, estableciendo plazas militares en Queule, Toltén e Imperial.

La minuciosa exploración de los ríos Imperial, Toltén y Queule era el “paso pre- 
vio" para la ocupación de "la costa de Araucanía" dispuesta por el Presidente. Como en expediciones anteriores, las ordenes reiteraban el propósito de "obtener datos fijos i seguros sobre la facilidad de su entrada i la capacidad que prestan sus aguas a la navegación, sobre sus riberas i el pais que atraviesan, i sobre las ventajas que pueden proporcionar al establecimiento de plazas militares i centros de poblaciones industriales." ${ }^{38}$ Para tal efecto, se ordenó al Comandante General de Marina que pusiera a disposición al Jefe encargado de estas operaciones, Teniente Coronel de Ejército Cornelio Saavedra, los vapores "Ancud", "Maule" i "Fósforo", con todos los pertrechos, víveres y artículos necesarios. Los vapores quedaron a cargo del Capitán de corbeta Juan López bajo las órdenes de Saavedra, quien le hizo llegar instrucciones más precisas sobre las tareas que debía desarrollar en la costa de La Frontera. ${ }^{39}$ En estas se constataba la urgencia de la exploración de los ríos Toltén y Queule, así como la necesidad de estudiar los lugares más convenientes para el establecimientos de plazas militares y poblaciones "que han de formarse bajo su amparo" teniendo cuidado de considerar su "fácil protección por mar i por los rios navegables." En sus instrucciones, Saavedra recomendaba a los expedicionarios emplear "un trato amistoso con las tribus indíjenas" buscando inspirarles confianza advirtiendo que, se informaran sobre el "ánimo de los indios" y estuviesen siempre en una actitud vigilante no olvidando "en ningun momento que están al frente de un enemigo astuto i receloso."

Los detalles de las exploraciones de 1866-7, son conocidos a través de tres documentos. Uno es el Diario de exploración del Capitán Juan López; otro, el parte del Teniente $2^{\circ}$ Santiago Rugg y por último, el Extracto del Diario del Teniente $1^{\circ}$ Francisco Vidal Gormaz ${ }^{40}$. Este último elaboró una serie de cartografía, debido a la riqueza de información y la comparación que podemos establecer con la de 1855 para nuestro análisis, hemos seleccionado el "Plano del Rio Tolten i plaza militar del mismo nombre. Levantado de orden del Supremo Gobierno por el Teniente $1^{\circ}$ de Marina $D^{\mathrm{N}}$. Francisco Vidal Gormaz. En 1866 i 1867. (figura 5). Es una carta cuya escala es 1:20.000, en la parte inferior derecha se encuentran las "Explicaciones" o simbología y un recuadro con "Notas" con detalles referidos a la dinámica de las mareas, la característica de la barra del Toltén, así como las de este río y algunos de sus afluentes, entre otros aspecto ${ }^{41}$. En cuanto a la "Explicaciones", las referencias están representadas por letras y símbolos. En el primer caso la A identifica la localización de los "Cuarteles de la plaza militar de Tolten"; B los torreones con artillería para la defensa del pueblo; C la plaza; D la casa del cacique Millapi, “jefe de la reducción indígena de Tolten"; E, el "Reducto de Collico" flanco por donde pudiera ser atacado

38 A.R.A., M.M.M. 1867, Exploración hidrográfica de la costa de Arauco. Federico Errázuriz al señor Comandante General de Marina. Santiago, diciembre 5 de 1867.

39 A.R.A., M.M.M. 1867, Exploración hidrográfica de la costa de Arauco. Cornelio Saavedra al Comandante del vapor Maule, Jefe de la exploración marítima sobre la costa de la Araucanía. Valparaíso, diciembre 8 de 1866. p.p. 122-124.

40 Sobre este marino, explorador y cartógrafo ver Vidal 2013, tomo 45. En particular el estudio introductorio efectuado por Juan Couyoumdjian, 2013.

41 Por la extensión de estas notas se hace inviable reproducirlas en este artículo. 
el fuerte. F, la cuadrícula del pueblo; y G, la "Casa de la Subdelegación de Tolten". Los símbolos dan cuenta del lugar apropiado para instalar el telégrafo; la dirección de la corriente de los ríos; y las palizadas en el lecho del río. En la parte central inferior del mapa bajo el escrito "Observaciones" están anotadas las coordenadas de localización del "Campanario de la Misión de Tolten" y la "Estremidad Sur de la barra del Rio Tolten".

Si lo comparamos con el mapa de 1855 se observa una diferencia sustantiva respecto de la información y el nivel de detalle que proporciona el plano de Vidal, en lo que refiere a los aspectos naturales y los de la población que habitaba dichos parajes. En el primer aspecto, debemos resaltar el nivel de detalle en la representación del río Toltén su morfología, profundidad, bancos, islas, curso de su corriente y la dinámica de la barra del mismo. Aspecto que se extiende a la geografía de su entorno, muchos de los "espacios en blanco" han sido llenados así es posible observar la localización de las dunas en la costa marítima, los "Bosques de excelentes maderas de construcción", la identificación de los "Bosques Impenetrables sobre terrenos mui pantanosos" o una "Hermosa Pradera" y próximos al fuerte un "Totoral", una “Laguna que se seca en el verano", la "Laguna de Tolten".

La presencia humana está contenida en el plano. Por las riberas del río quedó registrado habitaciones con su entorno cultivado, la mayoría no identificadas, en tanto en otras se consignó su morador como la del cacique Millapi, mencionada anteriormente, "Baldes", "Ramon" y "Cacique Manguepil". Al centro del plano se aprecia la misión religiosa y su cementerio, el fuerte, la plaza y las manzanas del pueblo algunas de las cuales están marcadas con una F y otras en blanco, tal vez una indicación de que no están pobladas, lo que anuncia el carácter de proyecto del mapa, una suerte de plano regulador que consigna el lugar de la expansión futura del pueblo.

La demarcación del "foso", así como el "Torreón" refuerzan la idea que estamos en presencia de un fuerte militar. Su localización estratégica se devela con los diversos caminos consignados como el de Queule a Tolten, el de Tolten al Imperial, el camino a Los Boldos, el "Unico camino de Tolten a Los Llanos" y en su ruta el sector de Collico, estratégico para la defensa del fuerte.

Este Plano confeccionado por Vidal Gormaz es un documento que contiene la dinámica de ocupación de la Araucanía. Un Estado más activo que había desplazado agentes religiosos y militares a territorio indígena, que exploraba sus tierras y establecía puntos de consolidación y avanzadas para futuras penetraciones. El plano resume esta nueva etapa, manifiesta la intensión de avanzar en la conquista y derrota militar mapuche en donde el detallado conocimiento geográfico jugaba un rol gravitante. Al mismo tiempo constituía un diagnóstico de las potencialidades de sus recursos y una proyección de la idea en que los fuertes también eran pensados como el germen de futuras ciudades. La fijación de los "espacios fugitivos" quedaba reflejada en la localización de los emplazamientos mapuche identificando, en algunos casos, a sus caciques. Los secretos de la geografía indígena, no sólo eran descubiertos sino que también representados en un sistema de información como el mapa, la 
conquista y reducción del territorio mapuche era una realidad, por el momento, en los planos.

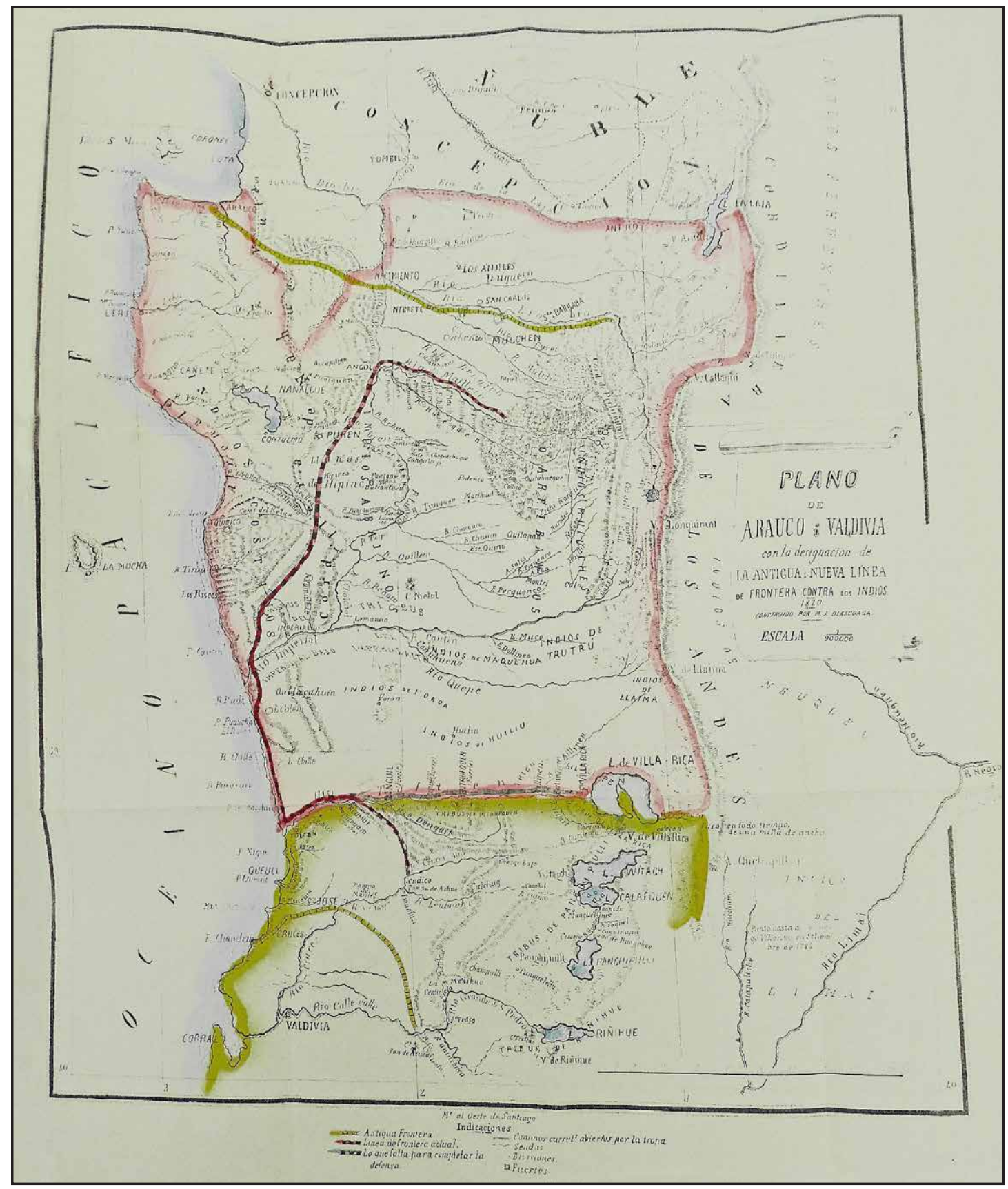

Figura 6.M. J. Olascoaga, "Plano de Arauco i Valdivia con la designación de la Antigua i Nueva línea de Frontera contra los Indios", 1870.

En enero de 1885 el joven capitán José Miguel Varela se presentaba ante su superior Alberto Novoa, comandante del "Escuadrón Húsares" de Angol. Éste lo recibió cordialmente, poniéndolo al día de los avances que en los últimos años había efectuado el ejército en la Araucanía. Entre los hitos, el comandante, destacaba la fundación de los fuertes Recabarren en Temuco a orillas del río Cautín y de Traiguén junto al río homónimo. Con entusiasmo le señalaba que “De esta manera se ha 
logrado controlar, aunque solo parcialmente, la inmensa zona comprendida entre el río Malleco, por el norte y el Toltén, por el sur, indicaba mostrándome, dice Varela, una gran carta de la zona que tenía clavada en una de las paredes de su oficina. Agregando que "A todo esto le llaman "territorio de colonización"... son varios millones de hectáreas con haciendas muy dispersas..."42 proseguía comentando el oficial.

Quince años antes otro mapa cobraba protagonismo, era el "Plano de Arauco i Valdivia con la designación de la Antigua i Nueva línea de Frontera contra los Indios. 1870. Construido por M. J. Olascoaga". (figura 6). Adjuntado por el coronel Cornelio Saavedra a un largo informe, fechado el 1 de junio de 1870, sobre las operaciones y trabajos practicados en el territorio indígena bajo su mando, que envió al Ministro de Guerra. Representaba este mismo territorio y había sido "trazado ligeramente según las exploraciones y estudios que se han hecho del territorio araucano, aprovechando la oportunidad de las últimas expediciones, y según otros reconocimientos especiales que mandé a practicar en la parte noreste de Valdivia y sur de Toltén, patentiza a primera vista el sistema que hemos adoptado para la reducción final de las tribus araucanas, los trabajos ya planteados y el proyecto de su terminación.

En vista de este ligero diseño, y mientras se publican científicamente verificadas las observaciones de los ingenieros que me han acompañado, V.S. podrá formarse una idea bastante exacta de la topografía general de aquellas regiones que hasta hoy eran poco conocidas." ${ }^{43}$ Escribía Cornelio Saavedra. Este informe y otros que abarcan desde 1861 a 1870 dieron forma al libro Documentos Relativos a la ocupación de Arauco. Que contiene los trabajos practicados desde 1861 hasta la fecha por el Coronel de Ejército D. Cornelio Saavedra y demás antecedentes que pueden contribuir a ilustrar el juicio de los Señores Diputados en la próxima discusión sobre el último proyecto del Ejecutivo. Un largo título que refleja el propósito de Saavedra, dejar sentado y difundir sus logros como Jefe del Ejército de Operaciones en el Litoral de Arauco e influir sobre la toma de decisiones sobre el proceso de ocupación de la Araucanía. Como sostiene Ravest este texto y los mapas fue editado y financiado por el Coronel Saavedra, y repartido entre sus colegas de la Cámara Baja, ya que Saavedra también era diputado, él pronto iba a dejar el Ejército y se discutía la estrategia y recursos de la ocupación de las tierras indígenas. ${ }^{44}$

Si bien el mapa que nos ocupada cuenta de la dinámica militar en La Frontera, sus destinatarios trascienden el circulo del ejército y por ello contiene una preocupación por ilustrar con claridad el escenario de guerra utilizando colores para estos efectos. Sin dejar de ser "preciso" busca ser didáctico. Ciencia, poder, representación, reducción, estaban contenidos en el mapa y explicitados en el texto escrito por Saavedra.

El mapa que nos ocupa esta construido a una escala 1:900.000, en que se de-

42 Parvex 2015, p. 287.

43 Saavedra 2009, tomo 43, p.210. También hemos podido revisar la versión original publicada en 1870 en Santiago por la Imprenta de la Libertad, que adjuntaba tres planos, los mismos de la presente edición que es la que referenciamos.

44 Revest Mora 2009. 
marcan límites administrativos de la Provincia de Arauco (en color rojo) y Valdivia (en color amarillo). Los logros de Saavedra en términos de conquista territorial al indígena están demarcado con una línea amarilla la "Antigua Frontera" y una línea de color granate la frontera actual (1870), todo ello demarcado en un espacio para la simbología, allí se enuncia otra línea de color verde-gris ${ }^{45}$ que representaría "lo que falta para completar la defensa" que sería la prolongación de la Línea del río Tolten desde Comui hasta las nacientes del río en el Lago Villarrica. En la simbología, o "indicaciones" como se escribe en el mapa, se identifican los "caminos carreteros abiertos por la tropa", las "sendas", las "divisiones" y los "Fuertes".

El mapa da cuenta de aspectos naturales como las hoyas hidrográficas y de relieve. En el caso de los ríos, éstos son localizados, demarcados e identificados ya que constituyen hitos naturales fundamentales en la estrategia militar de avance en territorio indígena. Por el norte la frontera se había trasladado del río BíoBío al Malleco y en el sur el esfuerzo estaba dado en consolidar el río Toltén como límite. Es por ello que se identifica el curso de los río Mulchén, Renaico, Lebu, Vergara, Traiguén, Imperial, Cautín Quepe, Allipen, entre otros. De la morfología se destaca la Cordillera de Los Andes, las serranías al oriente del Fuerte de Collipulli y algunos trazos de la Cordillera de la Costa. Al sur del Río Malleco y particularmente entre los ríos Imperial-Cautín y Toltén predomina el "blanco" en el mapa, prueba de que las exploraciones en esta zona no habían sido tan intensas como en otros sectores, muestra de ello es que la representación del Lago Villarrica es similar a la que dibujara Claudio Gay 34 años antes. Lo que contrasta con lo más cubierto de detalles en que son representadas la zona costera, las fronteras norte y sur.

Respecto de la población mapuche, el mapa evidencia un mayor conocimiento de su ubicación y establece una suerte de jerarquía reflejada en el tamaño de la letra, por una parte identifica grandes agrupaciones como "indios Costinos", "Indios Abajinos", "Indios Moluches o Arribanos", pero también las "Tribus del Imperial Bajo", “Tribus del Imperial Alto", a los "Indios de Voroa", "Indios de Huiliu”, "Indios de Llaima", "Indios de Trutru", "indios de Maquehua", cuyos textos son materializados una letra menor; incluso identifica a Lemunao ${ }^{46}$ en las proximidades de la confluencia de los ríos Chol Col y Cautín, cuya escritura es de menor tamaño que las anteriores. Esta característica diferenciadora, apreciable a través del tamaño de la letra, también es observable cuando se ubican y denominan los fuertes. Por ejemplo a Purén se le atribuye una mayor jerarquía que a Lumaco.

Hemos señalado que el mapa presentado por Saavedra al Ministerio de Guerra fue elaborado por Manuel J. Olascoaga, aspecto que merece otorgar un poco más de atención. Algunos años más tarde, al otro lado de la Cordillera de Los Andes, las tropas del general Roca llegaban a Choele-Choel, el 25 de mayo de 1879, punto neurálgico para la conquista de la Pampa. En el diario de campaña quedó registrado que la expedición había logrado "el más grande y definitivo triunfo que la República 45La reproducción del mapa de 2009 el verde es más intenso en tanto la versión original de 1870 el verde se diluye y da paso a un gris.

46 No es posible sostener si es en alusión al cacique o a la reducción. 
Argentina podía esperar... (el) obsequio de su geografía y topografía desconocidas, porque estas columnas han recorrido el desierto, fijando con inteligencia sus posiciones y distancias y han sorprendido los misterios hasta aquí mantenidos con la sagacidad del indio, dando por resultado una corrección radical en nuestros mapas de la Pampa" ${ }^{47}$.

Tres años más tarde José Manuel Olascoaga, el mismo que había confeccionado el mapa de Saavedra de 1870, elaboraba el "Plano del territorio de La Pampa y Río Negro y de las provincias chilenas que lo avecindan por el oeste". Así, en ambos lados de la cordillera iban siendo fijados los "espacios fugitivos" que representaban los territorios indígenas, y dando cuenta de los avances de los soldados de la nación. Su representación - reducción constituía una captura simbólica del territorio conquistado, una imagen general y específica sobre la cual se podía "actuar".

\section{Estado, Mapa y propiedad o ¿dónde están?, ¿de quién es?}

En las últimas décadas del siglo XIX y primeros años del XX, a la antigua Frontera mapuche habían llegado nuevos habitantes, aumentando la población significativamente y, contra todo pronóstico, los indígenas no habían desaparecido, tampoco se había producido su "asimilación" a la sociedad civilizada. El censo de 1907 fue una llamada de atención. Previo a éste, las estimaciones más favorable para los mapuches subían su población a no más de 80.000, el "Censo de Indios Araucanos", como se le llamó, los elevó a 101.000. Algo inquietante para el Estado-nación chileno, sin embargo, se afirmaba ahora no tienen continuidad territorial como antaño, están atomizados, dispersos por las provincias de Arauco, Malleco, Cautín y Valdivia. ${ }^{48}$ Este mismo censo registraba alrededor de 400.000 nuevos habitantes en las provincias señaladas. Así, la lucha por la tierra pasó a ser una constante de la historia de la Araucanía, las tensiones y conflictos una manifestación de dicha situación.

Consistente con el proceso de colonización, las representaciones militares fueron dando paso a las de la propiedad de la tierra. Si el censo respondía a la pregunta ¿cuántos son? el mapa podía ayudar a identificar ¿dónde están? y ¿de quién es? Esta pudo ser uno de las motivaciones centrales de la confección de dos cartas sobre propiedad en la "nueva Araucanía". Las Cartas Generales de las Provincias de Cautín (1916) (figura 7, detalle) y Malleco (1917) son una muestra del nuevo momento y los intereses de un Estado instalado en los territorio recientemente conquistados a los mapuche.

Confeccionadas por Nicanor Boloña, cartógrafo de la Oficina de Geografía y Minas de la Dirección General de Obras Públicas, si bien contiene aspectos hidrográficos y geomorfológicos del territorio, su discurso central es el de la división y propiedad de la tierra. Al centrar nuestro análisis en la representación de la Provincia de Cautín, similar a la de Malleco, es posible observar que su título contiene el mandante específico que es la "Inspección General de Colonización e Inmigración" 47 Olascoaga 1974, p. 223.

48Sobre los censos en Chile ver Pinto 2015. 
de cuyos archivos se obtuvo la información para su confección; su contenido: “Carta General de Colonización de la Provincia de Cautín"; el autor "Construida i dibujada por Nicanor Boloña la escala 1: 100.000bajo esta se escribe"Santiago Septiembre de 1916" e impresa en los "Talleres del Estado Mayor Jeneral".

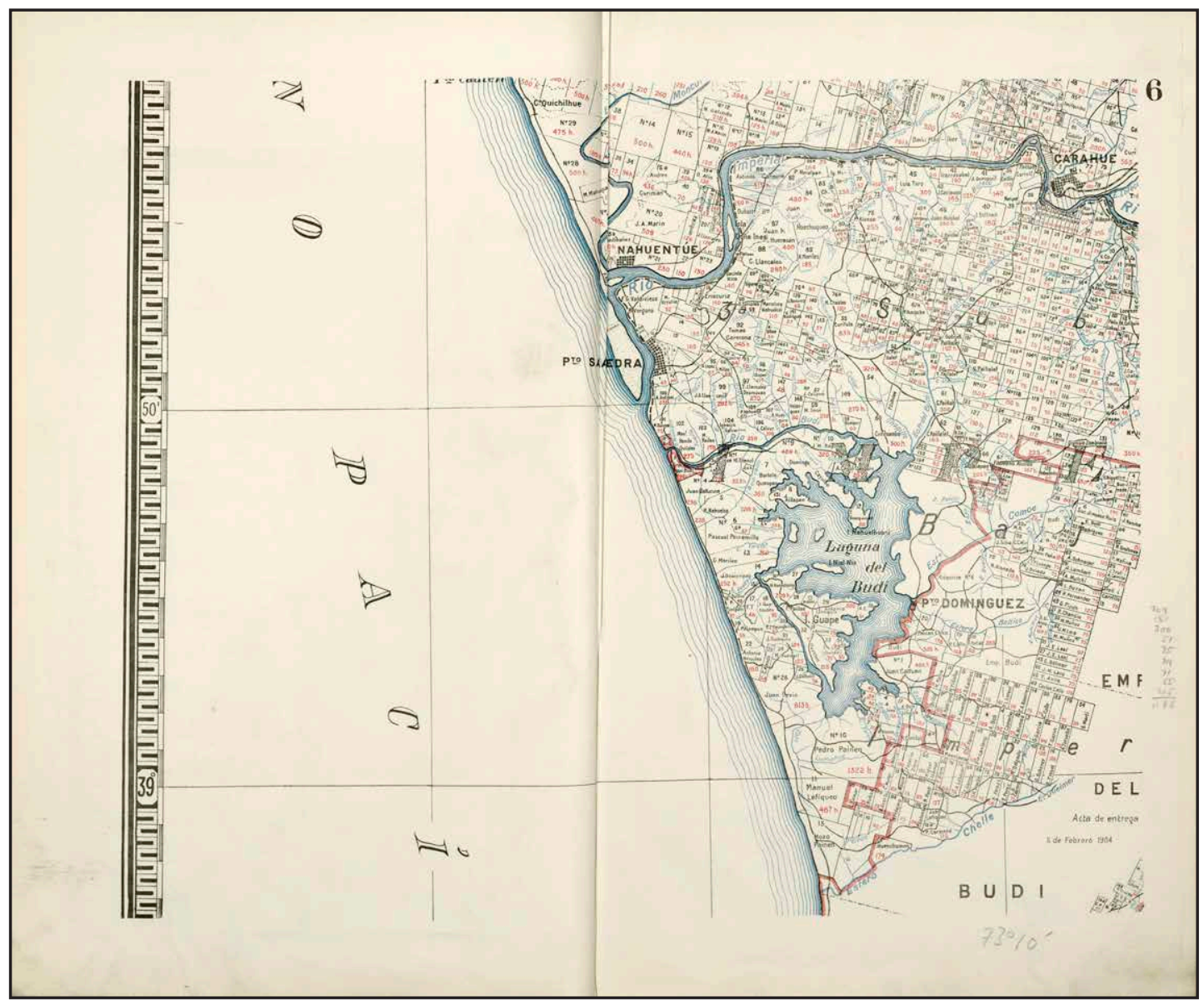

Figura 7.Nicanor Bolonia, detalle de la "Carta General de Colonización de la Provincia de Cautín", 1916.

En el recuadro de "Esplicacion" o simbología, ubicado en la parte inferior izquierda, se señala que las "Cifras negros, (son) numero de los lotes i sitios", las "Cifras rojas, cavidad en hectáreas", diferentes tipos de líneas representan caminos, ferrocarriles en explotación y en proyecto, los límites de Concesiones, de Subdelegaciones, Departamentos, de Provincias e Internacionales. Esta "Carta" está compuesta por 16 láminas de igual tamaño, una lámina en que se representa toda la provincia de Cautín y en las quince restantes una sección parcializada de la provincia que al unirlas forman la provincia. Esto posibilita ver los detalles de los accidentes geográficos del área representada y el de la división de la propiedad, con su número respectivo, las hectáreas que abarca y los propietarios de los terrenos. Un retrato minucioso de quienes son los propietarios, cuanta tierra poseen y donde están ubicadas. Así es posible ir observando el proceso de ocupación y redistribución de las tierras indígenas en la Araucanía. La constitución de la gran propiedad, las medianas y pequeñas 
quedan establecidas en el mapa. Es indudable, la carta es una muestra del proceso de ir fijando los "espacios fugitivos" del mundo mapuche, la división y delimitación de comunidades indígenas, la entrega de títulos de merced y la cartografía que cristaliza su presencia en términos territoriales dan cuenta de los procesos que los mapuches fueron experimentando a partir de la segunda mitad del siglo XIX, la reducción de su territorio no sólo era el resultado de una representación cartográfica, ésta evidenciaba la reducción de tierras que habían experimentado en poco más de medio siglo.

El mapa de Bolonia registra la presencia de algunos dispositivos empleados por el Estado para generar los procesos de transformación territorial, destacan los centros urbanos, aquellas pueblos o ciudades he se habían ido conformando al amparo de fuertes, misiones y estaciones del ferrocarril. Los caminos y vías del ferrocarril que posibilitaban la conectividad interna y de esta región con el resto del territorio nacional. Y en su conjunto el mapa era una suerte de retrato en que predominaban líneas rectas fruto de la división territorial, el teodolito y las mediciones matemáticas, construían figuras inexistentes algunas décadas antes.

$\mathrm{Al}$ amparo de este reconocimiento más detallado del territorio y, del proceso de ocupación y transformación, nuevas palabras se escribían sobre el mapa. Unos mantenían denominaciones dadas por el pueblo mapuche, otros eran bautizados con palabras ajenas a la lengua indígena. Sin duda la toponimia había cambiado dando cuenta de la nueva situación histórica. Un ejemplo en este sentido lo podemos dar con Puerto Saavedra. Un pueblo ubicado en la desembocadura del río Imperial. Originariamente los mapuches llamaban al lugar rulowe (el lugar de la vega o asentamiento en la vega) en 1850 se instaló una misión capuchina y el lugar fue conocido como "La Misión". Con las exploraciones y ocupación militar de la segunda mitad del siglo XIX el lugar y las casas que se fueron agrupando tomó el nombre de "Bajo Imperial". Para 1895 se construyó un plano que bautizó al pueblo como Puerto Saavedra, en honor a Cornelio Saavedra, militar a cargo de la Ocupación de la Araucanía, denominación que recoge Bolonia y se mantiene hasta el presente. ${ }^{49}$ Nombre que permanece hasta hoy.

A la "Carta" construida por Bolonia es posible aplicar las palabras que Harley escribió al observar los mapas y atlas históricos y de condado del siglo XIX de Norteamérica "lo que leemos es un discurso metafórico, tan grueso como un libro, acerca del orgullo rural inmigrante, de las utopías que se vislumbran, del orden y la prosperidad del paisaje. Estos mapas elogian la posesión de la tierra, privilegian las demarcaciones de las propiedades y hacen memorable las haciendas y los nombres de dueños de propiedad"50.

49En la actualidad existe un movimiento tendiente a recuperar el nombre original en lengua mapuche que seria, a juicio de ellos, Konün Traytrayko (la entrada del traytrayko, que sería el nombre del río Imperial, que es una palabra onomatopéyica derivada de traytray) sin embargo, otros señalan que sería Rulowe (el lugar de la vega o asentamiento en la vega). Esto muestra como los nuevos nombres fueron haciendo olvidar los originales. Para los nombres indígenas hemos tenido la colaboración de Margarita Canihuan.

50Harley 2005, pp. 76 y 77. 


\section{A modo de conclusión}

La ocupación de la Araucanía a partir de la segunda mitad del siglo XIX ha tenido diversos enfoques de estudio. Uno de ellos asociado a su transformación territorial, es nuestro caso, el de su representación a través de la cartografía. En este sentido es posible sostener que, como en otras latitudes, los mapas se constituyeron en un dispositivo de reducción, control, dominación y fijación de los "espacios fugitivos" del mundo indígena. Lejos de una aparente "neutralidad", los mapas constituyen documentos marcado por el contexto histórico e ideológico del tiempo en que fueron elaborados, una fuente significativa de aproximación a los procesos de representación de los espacios.

En el caso de la Araucanía, el análisis de los mismos nos permitió evidenciar distintos momentos por el que transitó el interés del Estado chileno por su anexión. Creemos que 1836 muestra un momento de inflexión con la aparición del “Borrador de un mapa de Chile", más allá de la precisión de este mapa hemos querido resaltar la ideología contenida en él, la imagen de una naciente república en la que está contenida la Araucanía, una suerte de programa o manifiesto visual de lo que debería ser el territorio nacional.

Con este propósito, el Estado desplazó hacia la Araucanía agentes "especializados" en la búsqueda de información y representación del territorio, entre otros hemos destacado a naturalistas, militares e ingenieros, los que fueron perfilando ciertos momentos que es posible identificar a través de los productos que generaron como fue la cartografía. Claudio Gay, Francisco Vidal Gormaz y Nicanor de Bolonia constituyen alguno de sus más claros representantes, a la vez que expresión de la exploración, ocupación y transformación del territorio mapuche. La ruta que transito el Estado chileno entre 1836 a 1916.

\section{Bibliografía}

BARROS ARANA, D. Claudio Gay su vida y sus obras. Estudio biográfico i crítico escrito por encargo del Consejo de la Universidad de Chile. Estudios histórico-bibliográficos. Santiago: Imprenta Cervantes, v. 5, 1909-1911.

COUYOUMDJIAN, J. Francisco Vidal Gormaz: su vida, su trayectoria profesional y la geografía náutica de Chile. In VIDAL, F. Exploraciones y reconocimientos hidrográficos. Santiago: Biblioteca Nacional, Pontificia Universidad Católica de Chile y Cámara Chilena de la Construcción, 2013.

CRAIB, R. Cartographic Mexico: A History of State Fixatonsan Fugitive Landscapes. Duke: University Press, 2004.

DE SOLÀ-MORALES, M. La identidad del territorio [En línea]. http://lub.upc. edu/web/Arxiu/Recerques/comarques/articles castella/identidad territorio cast. pdf(26 de octubre 2015) 
FLORES, J. La construcción de la Araucanía a inicios de la República. Claudio Gay e Ignacio Domeyko en la Araucanía. In GONZALEZ, Y. (ed.), Diálogos de Historia. Miradas y alcances de la investigación en Chile con enfoque regional. Temuco: Ediciones Universidad de La Frontera, 2015.

FOERSTER, R. MORENO, C. y RAMIREZ, J. Cartografía y conflicto en Rapa Nui (1888-2014). Santiago: Rapanui Press, 2014.

GARCIA, J.M. La representación histórica del inmenso azul: modelos de representación en la cartografía del Océano Pacífico. In SAGREDO, R. y MORENO, R. (coord.) El Mar del Sur en la historia. Ciencia, expansión, representación y poder en el Pacífico. Santiago: DIBAM, 2014.

GONZALEZ, J. Primeros levantamientos cartográficos generales de Chile con base científica: los mapas de Claudio Gay y Amado Pissis. Revista de Geografía Norte Grande, 2007, $\mathrm{n}^{\circ} 38$.

GONZALEZ, J. y BERNEDO, P. Cartografía de la transformación de un territorio: La Araucanía 1852-1887. Revista de Geografía Norte Grande, 2013, No 54.

GUARDA, G. y MORENO, R. Monumenta Cartigraphica Chiloensia. Misión, territorio y defensa. 1596-1826. Santiago: Pehuen, 2010.

HARLEY, J.B. La nueva naturaleza de los mapas. Ensayo sobre la historia de la cartografía. México: Fondo de Cultura Económica, 2005.

HOLLMAN, V. y LOIS, C. Geo-grafías. Imágenes e instrucción visual en la geografía escolar. Argentina: Paidós, 2015.

LEIVA, A. El primer avance a la Araucanía. Angol 1862. Temuco: Ediciones Universidad de La Frontera, 1984.

LLADÓ, B. Franco Farinelli. Del mapa al laberinto. Barcelona: Icaria, 2013.

NUÑEZ, A. La formación y consolidación de la representación moderna del territorio en Chile: 1700-1900. Santiago: Pontificia Universidad Católica de Chile, 2009.

OLASCOAGA, M.J. Estudio topográfico de la Pampa y Río Negro, Buenos Aires: Eudeba, 1974.

PARVEX, G. Un veterano de tres guerras. Recuerdos de José Miguel Varela. Santiago: Academia de Historia Militar, 2015

PINTO, J. La formación del Estado y la nación, y el pueblo mapuche. De la inclusión a la exclusión. Santiago: DIBAM, 2003.

PINTO, J. Los censos chilenos del siglo XX. Temuco: Universidad de La Frontera, 2015.

REVEST, M. Documentos relativos a la ocupación de Arauco. Santiago: Biblioteca Fundamentos de la Construcción de Chile, 2008.

ROSENBLITT, J. y SANHUEZA, M. Cartografía histórica de Chile. Santiago: Cámara Chilena de la Construcción, Pontificia Universidad Católica de Chile, Biblioteca Nacional de Chile, tomo 41, 2010.

SAAVEDRA, C. Documentos Relativos a la ocupación de Arauco. Que contiene los trabajos practicados desde 1861 hasta la fecha. Santiago: Cámara Chilena de la Construcción, Pontificia Universidad Católica de Chile, Biblioteca Nacional de Chile, 
tomo 43, 2009

SAGREDO, R. Geografía y nación. Claudio gay y la primera representación cartográfica de Chile. Revista de Estudios Geográficos, 2008, nº 266.

SAGREDO, R. El Atlas de Gay. La representación de una nación. In Claudio Gay Atlas de la Historia Física y Política de Chile. Tomos I y I. Santiago: Cámara Chilena de la Construcción, Pontificia Universidad Católica de Chile, Biblioteca Nacional de Chile, tomo 30, 2010.

SAGREDO, R y MORENO, R. (coord.). El Mar del Sur en la historia. Ciencia, expansión, representación y poder en el Pacífico. Santiago: DIBAM, 2014.

THROWER, N. J. W. Mapas y Civilización. Historia de la cartografía en su contexto cultural y social. Barcelona: Ediciones del Serbal, 2002.

VIDAL, F. Geografía Náutica de Chile. Santiago: Cámara Chilena de la Construcción, Pontificia Universidad Católica de Chile, Biblioteca Nacional de Chile, tomo 45 , 2013.

Ficha bibliográfica:

(c) Copyright: Jaime Flores Chávez, Alonso Azócar Avendaño, 2017.

(c) Copyright Scripta Nova, 2017.

FLORES CHÁVEZ, Jaime; AZÓCAR AVENDAÑO, Alonso. Mapas para el Estado. La representación de la Araucanía: 1836 -1916. Scripta Nova. Revista Electrónica de Geografía y Ciencias Sociales. [En línea]. Barcelona: Universidad de Barcelona, 1 de abril de 2017, vol. XXI, no 562. [ISSN: 1138-9788]. 